\title{
Cidadania e a Habitação Social ${ }^{1}$
}

Rute Imanishi Rodrigues ${ }^{2}$

\section{INTRODUÇÃO}

Os assentamentos urbanos precários, tais como as favelas e os loteamentos irregulares ou clandestinos, são objeto de políticas públicas de diversas ordens. Por um lado, representam a dimensão espacial da pobreza urbana, e são áreas prioritárias para políticas sociais, especialmente aquelas relacionadas à habitação. Por outro lado, permanecem no imaginário coletivo como áreas “ilegais", portadoras de um estatuto diferenciado perante a lei e frequentemente associadas à criminalidade.

A habitação de interesse social é a principal política pública relacionada aos assentamentos precários, mas esta deve ser compreendida dentro do conceito mais amplo de cidadania. Com efeito, a moradia digna consiste em boas condições de habitação e de serviços urbanos básicos, mas compreende também o acesso a escolas, postos de saúde, equipamentos culturais e de lazer, ou ao conjunto de direitos sociais.

Cabe notar que o conceito clássico de cidadania como um status social vinculado a um padrão de vida suficiente para levar uma vida digna (Marshall e Bottomore, 1992) relaciona-se com a formação do estado de bem-estar social na Europa, onde a habitação foi um dos pilares das políticas sociais, ao lado da previdência, da saúde e da educação (Esping-Andersen, 1990). No Brasil, assim como em outros países dos outrora chamados países "subdesenvolvidos" - hoje renomeados como global South - as favelas cresceram nos centros urbanos, sobretudo a partir dos anos 1950, formando comunidades populosas, às vezes de centenas de milhares de habitantes. As barriadas, os pueblos, são denominaçóes de assentamentos similares às favelas que se espalham pela América Latina e o Caribe, como também na África, no Oriente Médio, e em diversos países do continente asiático, entre eles a Índia (Davis, 2006). Para enfrentar os problemas destes assentamentos, é importante compreender como os Estados nacionais trataram, ou deixaram de tratar, a questão da habitaçáo social, do ponto de vista da garantia dos direitos sociais vinculados à noçáo de cidadania.

Neste texto, pretende-se apresentar o contexto nacional e os estudos realizados no âmbito da Diretoria de Estudos e Políticas do Estado, das Instituiçóes e da Democracia (Diest) nos últimos dez anos relacionados ao tema habitação e cidadania, com ênfase sobre as políticas públicas para os assentamentos precários.

\section{AS POLÍTICAS NACIONAIS DE HABITAÇÃO SOCIAL NO PASSADO RECENTE}

No período 2003-2014, a habitação de interesse social foi tratada com destaque pelo governo federal. Com a criação do Ministério das Cidades, em 2003, coordenaram-se os esforços para o planejamento de políticas nas áreas de habitação, transportes, saneamento, regularização fundiária, áreas de risco, entre outras. Em 2005, aprovou-se a Lei no 11.124 para a criação de um Sistema Nacional de Habitação de Interesse Social (SNHIS), que seria coordenado pelo Ministério das Cidades e 
reuniria todas as organizações públicas ligadas à habitação social, e contaria com a participação ativa do setor privado, de organizaçóes não governamentais e movimentos sociais. Tal sistema nacional seria sustentado por um Fundo de Habitação de Interesse Social, com o objetivo de "viabilizar para a população de menor renda o acesso à terra urbanizada e à habitação digna e sustentável" (Brasil, 2005). Para a construção desse novo ambiente institucional, o Ministério das Cidades estimulou a elaboração de planos de habitação e planos diretores municipais que, em grande medida, mapearam os assentamentos precários do país, definindo-os como zonas especiais de interesse social (ZEIS), passíveis de regularização com normas urbanísticas e fundiárias mais flexíveis, e prioritários para a política habitacional (Santos Júnior e Montandon, 2011).

Em 2007, o governo federal lançou o Programa de Aceleração do Crescimento (PAC), visando promover um conjunto de investimentos em infraestrutura, tendo como um dos eixos os investimentos em infraestrutura social e urbana. Dentro deste eixo, contava-se com ações de urbanização de favelas que faziam parte dos Programas Prioritários de Investimentos (PPI), onde pretendia-se realizar obras de impacto urbanístico em grandes favelas situadas em regiôes metropolitanas. Os projetos no âmbito do PPI incluíam também a construção de equipamentos sociais, tais como postos de saúde, escolas e creches, assim como áreas de lazer e centros culturais. As regras do programa previam porcentagens altas de investimentos em saneamento básico, novas habitações ou melhorias habitacionais, e prioridade para as realocaçóes (quando necessárias) em áreas contíguas às favelas. Posteriormente, a partir de 2010, o Programa Minha Casa Minha Vida (PMCMV) passou a atender a demanda por novas construçóes do PAC-Favelas, assim como foi amplamente utilizado para abrigar moradores removidos por outras obras também vinculadas ao PAC, além de atender situaçóes de desabrigados em função de desastres ambientais.

Ainda em 2007, o governo federal lançou o Programa Nacional de Segurança Pública com Cidadania (Pronasci), que incentivava a adoção do policiamento comunitário pelos governos estaduais, assim como um conjunto de açóes sociais e de acesso à justiça nos chamados territórios da paz, definidos como bolsóes de pobreza e violência nos grandes centros urbanos, coincidindo, portanto, com áreas de assentamentos precários (Ipea, 2007; Rodrigues, 2009).

Cabe observar que, tanto o PAC-Favelas quanto o Pronasci, foram programas federais realizados através de convênios com os estados e municípios e, em cada localidade, os entes federados se organizaram para a execução dos projetos através de arranjos institucionais diversos. Assim, no âmbito do PAC, as açôes de urbanização de favelas foram decididas e realizadas sem envolver, necessariamente, o conjunto de organizaçóes e fóruns participativos previstos no Sistema Nacional de Habitação de Interesse Social. Não obstante, o PAC-Favelas contava com um componente de trabalho técnico social, que promoveu uma série de projetos com as organizaçóes comunitárias nas localidades escolhidas para o programa (Oliveira, 2016).

No âmbito do Pronasci, os convênios com estados e municípios previam a execuçáo de um conjunto de programas de diversos ministérios a serem executados em territórios da paz, em parcerias com organizaçóes locais, assim como um montante de recursos para capacitar e equipar as polícias e o aparato de segurança pública dos estados em geral. Pretendia-se que a gestão do Pronasci fosse compartilhada entre o governo federal, estados e municípios, que deveriam coordenar um conjunto grande de programas diversos, envolvendo articulaçóes entre vários ministérios e secretarias entre os três níveis de governo, o que era apontado como um desafio (Ipea, 2007). Além disso, não estava 
claro como se daria a articulação entre as ações sociais e as de policiamento comunitário (Rodrigues e Motta, 2013).

No momento de lançamento destes dois programas federais - PAC-Favelas e Pronasci -, havia se formado um ambiente macroeconômico de expansão do emprego e da renda, permitindo financiar com folga os gastos governamentais através do Orçamento Geral da União, de onde provinham (a maior parte) os recursos para ambos os programas. O PAC-Favelas, por sua vez, era parte do componente do gasto público que realimentava o ciclo de expansão do emprego, estimulando a construção civil nas grandes cidades.

Pode-se dizer que, nesse período, predominaram as perspectivas otimistas sobre a transformação física e social dos assentamentos precários, na medida em que havia investimentos relativamente vultuosos em programas direcionados para a elevação dos padróes habitacionais e de infraestrutura urbana, assim como para açóes sociais e de policiamento comunitário nessas áreas. Contudo, tanto o PAC-Favelas quanto o Pronasci, ao serem implementados pelos governos estaduais e municipais, assumiram características locais específicas, que geraram diferentes percepçóes e avaliaçóes por parte de grupos de ativistas, especialistas da área, acadêmicos e moradores dos assentamentos nas cidades onde se desenvolveram.

Nesse ponto, cabe observar que, entre 2009 e 2011, o Ipea realizou uma pesquisa para avaliar o projeto de urbanização para o Complexo do Alemão, no Rio de Janeiro, no âmbito do PAC, utilizando o modelo lógico para avaliação de projetos. Na pesquisa qualitativa, observou-se que a percepçáo dos moradores sobre o programa era positiva, na medida em que as obras do PAC representavam uma esperança de mudar a representaçáo negativa do local, e as novas unidades habitacionais eram, no geral, bem avaliadas pelos beneficiários. Entretanto, criticava-se a falta de transparência quanto ao projeto a ser implementado, denunciavam-se práticas de clientelismo (sobretudo através das associaçóes de moradores) e manifestava-se temor (fundamentado em experiências anteriores) quanto à possibilidade de paralisação das obras e falta de manutenção dos equipamentos instalados (Andrade et al., 2011).

Porém, a crítica que mais se destacava no debate público naquele momento relacionava-se ao PMCMV, carro-chefe da política habitacional no período. Setores da Academia e movimentos sociais apontavam que o PMCMV era comandado essencialmente pelo setor privado, promovendo empreendimentos em localidades inadequadas, e não seguia as diretrizes dos planos municipais e do próprio plano nacional de habitaçáo. Assim, o PMCMV parecia estar descolado do planejamento em geral, e mais especificamente do desenho do sistema nacional de habitação de interesse social, proposto nos anos anteriores.

\section{OS ESTUDOS SOBRE HABITAÇÃO E CIDADANIA NO ÂMBITO DA DIEST}

No âmbito da Diest, os estudos sobre o tema da habitação social desenvolveram-se, até o presente, por meio das seguintes abordagens principais: i) urbanização e regularização fundiária das favelas; ii) direito à moradia e à cidade; iii) participação social em políticas urbanas; iv) capacidades estatais para a política habitacional; v) movimentos sociais por moradia; e vi) políticas públicas para moradores de rua. Além dessas áreas principais, os estudos sobre habitação desenvolveram-se em constante diálogo com grupos de pesquisadores de outras áreas na Diest, como pesquisas sobre justiça, direitos humanos, políticas de segurança pública, terceiro setor, grupos populacionais vulneráveis, desenvolvimento, entre outros. 
Os arranjos institucionais da política de habitação social, em nível macro, foram estudados no âmbito do projeto Estado, Democracia e Desenvolvimento no Brasil Contemporâneo: Arranjos Institucionais de Políticas Críticas ao Desenvolvimento (Gomide e Pires, 2013). Dentro desse projeto, o arranjo institucional do PMCMV foi avaliado com o objetivo de inferir se tal arranjo incentivava ou não a participação de amplos setores envolvidos na política, se favoreciam ou não a coordenação de sua implantação, assim como o alcance das metas propostas (Loureiro, Macário e Guerra, 2013). $\mathrm{O}$ estudo concluiu que, mesmo tendo alcançado as metas estabelecidas, com mecanismos de gestáo e controle eficientes, o arranjo institucional do PMCMV não se mostrava "politicamente legitimador", na medida em que atores sociais importantes na área não eram contemplados nas arenas decisórias.

No nível local, a experiência com a pesquisa sobre o projeto do PAC para o Complexo do Alemão (Andrade et al., 2011) motivou uma pesquisa da Diest sobre a história das políticas públicas para as favelas no Rio de Janeiro, tendo como estudo de caso aquele conjunto de favelas. Este estudo permitiu o aprofundamento necessário para abordar a estrutura fundiária das favelas - ou o aspecto da legalidade das ocupaçóes (direito à moradia) -, como também os arranjos institucionais no nível microterritorial para a implementação de políticas públicas naquela região. A estratégia metodológica utilizada foi realizar um estudo etnográfico reunindo narrativas de idosos moradores do Complexo do Alemão e uma pesquisa documental sobre a papel do componente fundiário nas políticas públicas para as favelas do Rio de Janeiro, e sobre o histórico fundiário do Complexo do Alemão (Rodrigues et al., 2013).

Os resultados dessa pesquisa foram relevantes, na medida em que corroboraram nossa hipótese de que as políticas públicas para as favelas do Rio de Janeiro entre 1930-1964 ajudaram a consolidá-las, sobretudo nos subúrbios. Tudo indica que os governos locais atuaram para a estabilização dos conflitos fundiários urbanos, através da criação de assentamentos estatais, e a desapropriação de terrenos privados ocupados por favelas, consolidando-as, a despeito da situação de ilegalidade/irregularidade fundiária perante a legislação. Ao mesmo tempo, a administração pública atuou para a introdução de serviços urbanos básicos nessas áreas, porém em parcerias com organizaçóes locais, notadamente as associaçóes de moradores (Rodrigues, 2014; Couto e Rodrigues, 2015). ${ }^{3}$ Os resultados da pesquisa foram discutidos no seminário Favelas do Rio de Janeiro, percurso histórico e estatuto legal, promovido pelo Ipea em 2013, reunido especialistas, acadêmicos, gestores públicos, e ativistas de organizaçóes não governamentais.

Em 2014, a Diest promoveu um seminário de estudo do espaço com o tema Direito à Cidade, teoria e prática - regulação sobre o uso do solo na época dos megaeventos, em parceria com a Universidade de Tulane, dos Estados Unidos, e o Observatório das Metrópoles, no Rio de Janeiro, reunindo acadêmicos, gestores públicos e ativistas de organizaçôes não governamentais (Rodrigues, 2016a). Nesse seminário, procurou-se trazer para o centro do debate a questão da propriedade fundiária nas favelas, que passavam por processos de remoção vinculados às obras para a Copa e as Olimpíadas. No âmbito desse projeto, a Diest fomentou uma pesquisa sobre a funçáo social da propriedade e o direito à cidade na legislação brasileira (Crawford, 2017).

Ao longo dos anos, construiu-se uma rede relacionamento entre pesquisadores do Ipea e pesquisadores de outras instituições em áreas correlatas à habitação social, além de gestores e ativistas com atuação em favelas do Rio de Janeiro. Por meio de uma rede de pesquisadores que realizava

3. A pesquisa gerou ainda um trabalho etnográfico reunido em um caderno de memória social. 
pesquisas de campo no Complexo do Alemão, organizou-se um livro reunindo um conjunto de artigos sobre políticas públicas naquelas favelas, buscando jogar luz sobre as práticas e instituiçóes locais para a implementação de políticas públicas em áreas de favelas (Rodrigues, 2016c).

Em parceria com o Observatório das Metrópoles, a Diest participou, por meio do programa de mestrado profissional (então gerido nesta diretoria), da realização do curso de extensão universitária "Políticas públicas e direito à cidade", para a formação de agentes sociais, em 2017 e 2018. O curso foi realizado na Universidade Federal do Rio de Janeiro (UFRJ), em parceria com um conjunto de organizaçôes da sociedade civil, e contou com a participação de pesquisadores da Diest na equipe didática e de professores (Santos Júnior et al., 2017).

A relação entre a participação social, a habitação e a cidadania foi estudada por Avelino (2016, p. 133). Nesse trabalho, apresentam-se conceitos sobre a formação dos movimentos sociais urbanos, mostrando que a "agregação social em torno de necessidades coletivas não atendidas passa a ser uma prática de sobrevivência para os indivíduos submetidos a esta privação", e que a dupla relação entre "carência e violência" por parte do Estado a que estão submetidos estes grupos, configuram um tipo específico de "segregação", que não é apenas espacial, mas afeta o exercício da cidadania. É a partir das ações destes movimentos que surgem os chamados instrumentos de envolvimento da sociedade na gestão democrática da cidade, tais como o orçamento participativo, os conselhos de políticas públicas, as conferências, as modalidades de democracia direta, as conferências, as audiências e as consultas públicas. Avelino (2016), entretanto, problematizou o alcance efetivo desses instrumentos e discutiu as práticas de democracia direta como estratégias dos movimentos sociais urbanos.

Outra linha de pesquisas da Diest dentro do tema da habitação social refere-se à população em situação de rua. O estudo pioneiro de Natalino (2016), estimou a população de rua no país utilizando dados do Censo do Sistema Único da Assistência Social (Censo Suas), para 2015, recomendando esse tipo de levantamento pelos municípios para fomentar a inclusão desse grupo nas atividades de vigilância socioespacial. As políticas públicas para a população em situação de rua também foram abordadas por Silva, Natalino e Pinheiro (2020), que realizaram um levantamento das medidas emergenciais adotadas pelos governos municipais na maior parte das capitais do Sudeste e do Nordeste, em meio à pandemia da Covid-19, para atender a este segmento da população.

\subsection{Estudos comparativos}

Entre fins de 2013 e início de 2014, a Diest apoiou um período de licença-capacitação para uma pesquisa comparativa entre as políticas para as favelas no Brasil e nos Estados Unidos, onde verificou-se que as políticas de slum clearance (remoção de favelas) foram recorrentes nos Estados Unidos, sobretudo nas décadas de 1940-1960, como parte integrante da construção do sistema de public housing naquele país. Constatou-se, nessa visita, a importância do componente racial para a estigmatizaçáo da pobreza urbana para os norte-americanos, inclusive nos conjuntos habitacionais (housing projects), que substituíram os antigos slums. A partir dos anos 1980-1990, o sistema de public housing passou a ser desmantelado e substituído por um sistema de vouchers (auxílio-aluguel), transferindo para o setor privado a maior parte da oferta de habitação social.

Em 2017, por meio da coordenação de instituiçôes e desenvolvimento da Diest, desenvolveu-se um estudo sobre o papel da habitação social para o desenvolvimento econômico, utilizando o caso da Inglaterra como exemplo. Naquele país, os slums eram considerados entre os principais problemas 
das grandes cidades no século XIX, mas foram substituídos por habitação pública, ao longo do século XX até a década de 1970, através de forte planejamento urbano e regional e construção de um amplo sistema de habitaçóes municipais (council housing) (Rodrigues, 2018).

No início de 2020, a Diest apoiou um período de licença-capacitação para uma pesquisa por três meses na Universidade de Bristol, na Inglaterra, sobre a habitação social. Constatou-se a sua importância para o estado de bem-estar social na Inglaterra, assim como os processos de privatização do setor a partir dos anos 1980, que reduziram o tamanho do sistema público e, ao mesmo tempo, transferiram boa parte da gestấo para housing associations. O desmantelamento do sistema público de habitação na Inglaterra conduziu à piora das condições habitacionais de parcela expressiva da população, e é alvo de críticas por parte de amplo espectro político.

Tanto no caso dos Estados Unidos quanto na Inglaterra, o desmantelamento do sistema de gestão estatal de habitação não significou a redução expressiva dos gastos do governo com a habitação social, mas sim a utilização de habitaçóes do setor privado (pagas com o auxílio-aluguel), assim como a transferência de parte da gestão do sistema para organizaçôes não governamentais.

\subsection{Acompanhamento de conjuntura}

A partir de 2016, com o processo de impeachment da presidente Dilma Rousseff, organizou-se no Ipea um trabalho de acompanhamento da conjuntura político-institucional interdiretorias, que registrou um momento de ruptura a partir do qual o entendimento dos problemas a serem tratados pelas políticas do governo federal mudou. No que diz respeito às políticas para os assentamentos precários, isso significou o abandono das políticas sociais explicitamente direcionadas a eles, e o reforço das políticas de repressão policial, que frequentemente ocorrem nessas áreas.

Em 2018, na coordenação de Justiça e Cidadania da Diest, realizou-se um trabalho de acompanhamento da intervenção federal no Rio de Janeiro, no qual constou-se que o foco da atuaçáo das forças militares foram as favelas da cidade. Neste contexto, formaram-se diversos "observatórios" em universidades, organizações não governamentais e parlamento, buscando dar visibilidade às violaçôes de direitos humanos que são recorrentes neste tipo de operação. A Diest produziu um relatório de pesquisa documentando as operaçóes em favelas, contabilizando os casos de violência letal. Constatamos, nesse trabalho, que durante a intervençáo houve recorde de mortos pela polícia no Estado, e que o total de mortos por militares foi maior (em termos absolutos e relativos) que em qualquer outra operação da lei e da ordem. Durante essa pesquisa, utilizamos o método da observaçáo participante, acompanhando fóruns de direitos humanos e, especialmente, o Circuito Favelas por Direitos, promovido pela Ouvidoria Externa da Defensoria Pública do Estado do Rio de Janeiro (Rodrigues e Armstrong, 2019). Os resultados desse trabalho foram discutidos em um seminário, em conjunto com o Observatório da Intervenção do Centro de Estudos da Segurança Pública e Cidadania (Cesec) e as defensorias públicas do estado e da Uniáo, no Rio de Janeiro.

\section{POLÍCIAS DE HABITAÇÃO SOCIAL NO PRESENTE, TENDÊNCIAS E LACUNAS}

No governo Temer, a partir de 2016, o principal programa habitacional conduzido pelo Ministério das Cidades, o PMCMV, teve suas contrataçôes praticamente paralisadas, e lançou-se um programa destinado a "melhorias habitacionais" para a população de baixa renda, o Programa Cartáo Reforma, com orçamento reduzido, e que não chegou a ser implementado. Posteriormente, com a posse do 
governo Bolsonaro, o Ministério das Cidades foi extinto e suas funçóes incorporadas (assim como o Ministério da Integração Nacional) ao novo Ministério do Desenvolvimento Regional (MDR). Em agosto de 2020, o MDR lançou o Programa Casa Verde Amarela (MP no 996/2020 em tramitação), que substituirá o PMCMV, e deve incorporar um programa de melhorias habitacionais, aluguel social e regularização fundiária. Não obstante, devido à rigidez da política fiscal, preveem-se baixos subsídios no programa, o que deve inviabilizar a produção de novas habitaçóes para as faixas de renda mais baixas, que ficariam restritas ao componente de regularização fundiária do programa.

No meio acadêmico, o momento atual tem aberto espaço para os estudos do tipo balanço das políticas urbanas e habitacionais dos governos Lula e Dilma. Os balanços preliminares sobre o conjunto de obras do PAC para a urbanização de assentamentos precários permitem afirmar que os resultados do programa não foram homogêneos entre os municípios, mas apresentaram resultados positivos na maior parte dos casos e se desenvolveram em grande medida com as especificidades derivadas das práticas locais para a urbanização de favelas (Cardoso e Denaldi, 2018).

Entretanto, constata-se que já existem camadas de urbanização em boa parte das favelas (Cardoso e Denaldi, 2018). Tais camadas são sobreposiçóes das obras que ocorreram ao longo do tempo, e indicam que os projetos de urbanização não conseguiram "congelar" a estrutura das favelas, sobretudo as grandes, que permanecem como locais de contínua multiplicação de habitaçóes, à revelia dos enquadramentos e padróes mínimos de lotes e edificaçóes projetados. Tal dinâmica tem efeitos negativos sobre a manutenção dos serviços urbanos básicos, já que a eficiência desses serviços (como o saneamento básico) depende dos parâmetros construtivos. A regularização fundiária, isoladamente, não tem capacidade de alterar esta dinâmica.

As pesquisas da Diest mostraram que a gestão dos serviços urbanos em favelas é um aspecto importante desse problema e tem caráter político e institucional. Com efeito, tal gestão envolve as relaçóes entre os governos locais e as associaçóes de moradores, principais parceiras dos governos locais para a implementação de políticas públicas em favelas. As obras do PAC-Favelas promoveram a construção de novas habitaçóes dentro do perímetro dos assentamentos, ou em áreas contíguas, que produziram setores onde a gestão dos serviços urbanos tende a ser feita da mesma forma que nas áreas formais da cidade. Esse é um fator positivo, desde que sejam estipuladas tarifas sociais para o pagamento das taxas correspondentes aos serviços. A conjuntura atual é adversa para a continuidade da construção habitacional para as faixas de renda mais baixa, e coloca-se no horizonte da formulação de políticas o desafio de estruturar e gerir um sistema nacional de habitaçáo, considerando todas as instituições públicas, privadas e não governamentais que atuam na área.

Observa-se que as pesquisas sobre os assentamentos precários no país (internas e externas ao Ipea) evoluíram no que diz respeito à identificação destes assentamentos, que passaram a ser incorporados aos planos diretores municipais como áreas prioritárias para a política habitacional e de regularização fundiária. Porém, ainda existem lacunas importantes a serem preenchidas, tais como a compreensão do papel das políticas governamentais para os processos históricos de formação e consolidação desses assentamentos nas diversas cidades do país; e a assimilação do conjunto de organizações e práticas político-institucionais que configuram as políticas habitacionais, nas diferentes esferas e níveis de governo, a partir dos quais poderia ser concebido o funcionamento do sistema nacional de habitação de interesse social. 
Este texto relacionou um conjunto de pesquisas já realizadas pela Diest, abrangendo aspectos político-institucionais das políticas públicas para os assentamentos precários, porém, muitos deles desenvolvidos através de estudos de caso. Caberia desenvolver, também, pesquisas mais abrangentes, em âmbito regional e nacional sobre estes aspectos do problema.

\section{REFERÊNCIAS}

ANDRADE, C. C. et al. Intervenção sociourbanística no Complexo do Alemáo: Programa de Aceleração do Crescimento. Brasília: Ipea, 2011.

AVELINO, D. P. Cidade e cidadania, consideraçóes sobre a gestão democrática na política urbana brasileira. In: COSTA, M. A. O estatuto da cidade e a Habitat III: um balanço de 15 anos da política urbana no Brasil e a nova agenda urbana. Brasília: Ipea, 2016.

BRASIL. Casa Civil. Lei no 11.124, de 16 de junho de 2005. Dispóe sobre o Sistema Nacional de Habitação de Interesse Social - SNHIS, cria o Fundo Nacional de Habitação de Interesse Social FNHIS e institui o Conselho Gestor do FNHIS. Diário Oficial da Uniáo, Brasília, 17 um. 2005.

CARDOSO, A. L.; DENALDI, R. Urbanizaçáo de favelas no Brasil: um balanço preliminar do PAC. Rio de Janeiro: Letra Capital, 2018.

COUTO, P. B.; RODRIGUES, R. I. A gramática da moradia no Complexo do Alemáo: história, documentos e narrativas. Brasília: Ipea, 2015. (Texto para Discussão, n. 2159).

CRAWFORD, C. A funçáo social da propriedade e o direito à cidade: teoria e prática atual. Brasília: Ipea, 2017. (Texto para Discussão, n. 2282).

DAVIS, M. Planeta favela. São Paulo: Boitempo, 2006.

ESPING-ANDERSEN, G. The three worlds of welfare capitalism. Cambridge: Polity Press, 1990.

GOMIDE, A. Á.; PIRES, R. Arranjos institucionais de políticas críticas para o desenvolvimento. Boletim de Análise Político-Institucional, n. 3, p. 71-75, 2013.

IPEA - INSTITUTO DE PESQUISA ECONÔMICA APLICADA. Uma nova política federal para a segurança pública: o Programa Nacional de Segurança com Cidadania (Pronasci). Boletim de Políticas Sociais, n. 15, 2007.

IPEA - INSTITUTO DE PESQUISA ECONÔMICA APLICADA; CAIXA - CAIXA ECONÔMICA FEDERAL. A intervençáo sócio-urbanística no Complexo do Alemáo. Brasília: Ipea, 2010.

LOUREIRO, M. R.; MACÁRIO, V.; GUERRA, P. Democracia, arenas decisórias e políticas públicas: o Programa Minha Casa, Minha Vida. Brasília: Ipea, 2013. (Texto para Discussão, n. 1886).

MARSHALL, T. H.; BOTTOMORE, T. Citizenship and social class. London: Pluto Press, 1992.

NATALINO, M. A. C. Estimativa da populaçáo em situaçáo de rua no Brasil. Brasília: Ipea, 2016. (Texto para Discussão, n. 2246). 
OLIVEIRA, B. C. Políticas públicas e participação social no PAC das Favelas. In: RODRIGUES, R.I. Vida social e política nas favelas: pesquisas de campo no Complexo do Alemão. Brasília: Ipea, 2016. p. 95-114.

RODRIGUES, R. I. Diagnóstico e desempenho recente do Programa Nacional de Segurança Pública com Cidadania. In: CARDOSO JÚNIOR, J. C. Brasil em desenvolvimento: Estado, planejamento e políticas públicas. Brasília: Ipea, 2009. v. 3.

. Os parques proletários e os subúrbios do Rio de Janeiro: aspectos da política governamental para as favelas nas décadas de 1930 e 1960 . Brasília: Ipea, 2014. (Texto para Discussão, n. 2016).

. O direito à cidade na Academia e nas ruas. Boletim de Análise Político-Institucional, n. 9, p. 39-45, 2016 a.

. Uma construção complexa: necessidades básicas, movimentos sociais, governo e mercado. In: RODRIGUES, R. I. Vida social e política nas favelas: pesquisas de campo no Complexo do Alemão. Rio de Janeiro: Ipea, 2016 b.

. Vida social e política nas favelas: pesquisas de campo no Complexo do Alemão. Rio de Janeiro: Ipea, 2016c.

. De volta aos clássicos, notas sobre o desenvolvimento e a habitação de interesse social. Boletim de Análise Político-Institucional, n. 16, p. 93-98, 2018.

. A covid-19 a falta de água nas favelas e o direito à moradia no Brasil. Brasília: Ipea, 2020. (Nota Técnica, n. 39).

RODRIGUES, R. I.; ARMSTRONG, K. C. A intervenção federal no Rio de Janeiro e as organizaçóes da sociedade civil. Rio de Janeiro: Ipea, 2019. (Relatório de Pesquisa).

RODRIGUES, R. I. et al. Histórico fundiário e da urbanização do Complexo do Alemão. Rio de Janeiro: Ipea, 2013.

RODRIGUES, R. I,; MOTTA, E. A pacificação das favelas do Rio de Janeiro e as organizaçóes da sociedade civil. Boletim de Análise Político-Institucional, n. 4, out. 2013.

SANTOS JÚNIOR, O. A. et al. Políticas públicas e direito à cidade: programa interdisciplinar de formação de agentes sociais. Rio de Janeiro: Letra Capital, 2017.

SANTOS JÚNIOR, O. A.; MONTANDON, D. T. Os planos diretores municipais pós-Estatuto da Cidade: balanço crítico e perspectivas. Rio de Janeiro: Letra Capital, 2011.

SILVA, T. D.; NATALINO, M.; PINHEIRO, M. B. População em situaçáo de rua em tempos de pandemia: um levantamento de medidas municipais emergenciais. Brasília: Ipea, 2020. (Nota Técnica, n. 74). 
